\section{Casa Siloé: a história de uma ONG para crianças portadoras de HIV/aids}

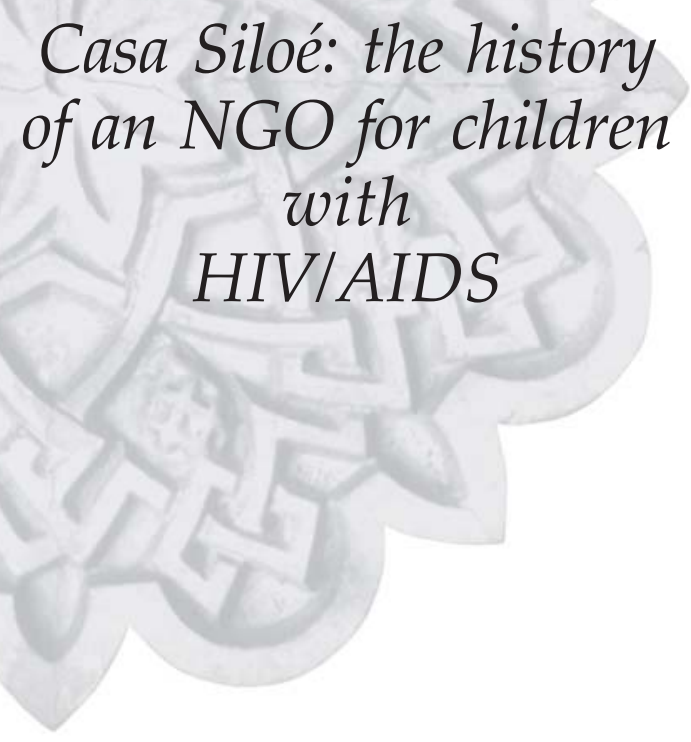

Maria de Fatima de Oliveira Andrade

Mestre pelo Programa de Pós-Graduação em Ciências da Secretaria de Estado da Saúde de São Paulo Rua Nova dos Portugueses, 1092 02462-081 São Paulo - SP Brasil oliveandrade@osite.com.br

Maria Cezira Fantini Nogueira Martins Instituto de Saúde da Secretaria de Estado da Saúde de São Paulo Av. Onze de Junho, 1291/102 04041-054 São Paulo - SP - Brasil mcezira@yahoo.com.br

Cláudia Maria Bógus

Faculdade de Saúde Pública da Universidade de São Paulo Rua Francisco Bayardo, 551/142 05020-010 São Paulo - SP - Brasil claudiab@usp.br
ANDRADE, Maria de Fatima de Oliveira; MARTINS, Maria Cezira Fantini Nogueira; BÓGUS, Cláudia Maria. Casa Siloé: a história de uma ONG para crianças portadoras de HIV/aids. História, Ciências, Saúde Manguinhos, Rio de Janeiro, v.14, n.4, p.1291-1311, out.-dez., 2007.

Traça um histórico da Casa Siloé, casa de apoio de orientação religiosa católica que abriga crianças portadoras do vírus da imunodeficiência humana e/ou com a síndrome da imunodeficiência adquirida, e discute sua atuação. $\mathrm{O}$ artigo resulta de estudo de abordagem qualitativa, que utiliza técnicas da história oral e análise documental. Foram entrevistados oito informantes-chave: o presidente da instituição; dois coordenadores que trabalharam na casa; um membro da sociedade mantenedora; uma assistente social voluntária; um membro do Fórum de ONGs/aids estadual, um médico e uma psicóloga do serviço público estadual. Abordam-se os temas: a Igreja católica e a aids; a mobilização comunitária; a Casa Siloé, o Estado e a sociedade civil; a avaliação e as perspectivas do projeto.

PALAVRAS-CHAVE: casas de apoio; aids; Casa Siloé; organizações não-governamentais; participação comunitária; Brasil.

ANDRADE, Maria de Fatima de Oliveira; MARTINS, Maria Cezira Fantini Nogueira; BÓGUS, Cláudia Maria. Casa Siloé: the history of an NGO for children with HIV/ AIDS. História, Ciências, Saúde - Manguinhos, Rio de Janeiro, v.14, n.4, p.1291-1311, Oct.-Dec. 2007.

Casa Siloé (Siloam House) is a Catholic support house that shelters children with human immunodeficiency virus or acquired immunodeficiency syndrome. The article presents a history of the institution and discusses its work. A qualitative approach was used, relying on oral history techniques and documental analysis.

Eight key informants were interviewed: the president of the institution, two coordinators who worked at the home, a member of the supporting foundation, a volunteer social worker, a member of the state NGO/AIDS forum, a physician, and a psychologist from the state public service. Topics addressed include the Catholic Church and AIDS, community mobilization, the Casa Siloé, the State and civil society, and project evaluation and outlook.

KEYWORDS: support houses; AIDS; Casa Siloé; nongovernmental organizations; community participation; Brazil. 
A síndrome da imunodeficiência adquirida (aids) é uma doença caracterizada pela deficiência do sistema imunológico do indivíduo. $\mathrm{O}$ agente causador da aids é o vírus da imunodeficiência humana (HIV), que destrói lentamente um tipo de célula de defesa denominado linfócito CD4, principal responsável pela resposta imunológica. Os mecanismos de transmissão do HIV são a relação sexual (homo ou heterossexual), a transfusão de sangue, o uso compartilhado de agulhas não esterilizadas entre usuários de drogas injetáveis e a transmissão da mãe para o filho durante a gestação, parto ou amamentação (transmissão vertical).

A epidemia da aids provocou, em nossa sociedade, manifestações de preconceito e intolerância para com as diferenças, em especial com relação às minorias sexuais. Em contrapartida, propiciou a criação de novas fórmulas de intervenção social e superação de limitações ético-morais. Sob esse ponto de vista, merecem destaque a ação e o discurso das organizações não-governamentais (ONGs) ligadas ao combate dessa doença que, ao terem a clara percepção da necessidade de intervenção imediata sobre a epidemia, buscaram propostas de atuação e contribuíram para reversão de ações discriminatórias e segregacionistas (Galvão, 1997a; Marques, 2002; Góis, 2004a).

Na década de 1980 surgiram as primeiras casas de apoio para pessoas com aids, como espaços de acolhimento para doentes que não podiam contar com apoio familiar (Villela, 1999). Com o aumento do número de casos por via heterossexual, passou a haver uma expressiva participação das mulheres no perfil epidemiológico da doença, cuja conseqüência direta foi o progressivo aumento da transmissão vertical; além disso, a morte materna por aids trazia, como conseqüência, a orfandade (Nichiata, 2001). Surgiram, então, as casas de apoio para crianças, ligadas a segmentos variados da sociedade civil, como por exemplo a Casa Vida - ligada à Arquidiocese de São Paulo -, o Centro de Convivência Infantil Filhos de Oxum - ligada ao Candomblé -, a Associação Evangélica de Apoio e Solidariedade a Pessoas com Aids (Praids), que, ligada à religião protestante, atende crianças e adultos, e a Associação Aliança pela Vida (Alivi), de orientação católica.

Segundo Sanches (1999, p.57), "as casas de apoio, dirigidas às crianças órfãs ou sem família, portadoras do HIV/aids, constituem uma alternativa válida (muitas vezes a única possível) para uma esperança de sobrevida física e de saúde psíquica para essas crianças". Sua estrutura varia de acordo com a demografia, demanda e proposta de trabalho. De modo geral, oferecem cuidado à saúde, moradia, suporte emocional e ativa intervenção no restabelecimento dos vínculos familiares, para uma futura reorganização de vida (Abadia-Barrero, 2002). 
Em 2001, o Ministério da Saúde, em norma conjunta com o Centro de Vigilância Sanitária (CVS) e o Centro de Referência e Treinamento em DST/Aids (CRT/DST/Aids) assim definiu 'casa de apoio':

Estabelecimento de interesse à saúde destinado a abrigar crianças e adolescentes portadores assintomáticos do HIV e crianças e adolescentes que tenham apresentado os primeiros sintomas e sinais da aids, com ausência ou pequena dificuldade de locomoção, que necessitem de assistência psicossocial, uso de equipamentos com finalidades terapêuticas (inalador portátil e/ou equipamento de complexidade tecnológica assemelhada) e cuidados especiais. (Brasil, 2001)

Considerando que, após duas décadas do início da epidemia, o registro e a análise das experiências da sociedade civil relacionadas à aids em nosso meio revelam as respostas da sociedade moderna ante um grave problema de saúde pública (Marques, 2002), o estudo do histórico de uma casa de apoio como a Casa Siloé permite entender como surgiu e se manteve essa iniciativa para lidar com uma situação de emergência, como eram, em 1994, a morte materna e a orfandade. Esse estudo permite também uma visão em nível microscópico de uma ação, tentando superar as generalizações sobre a história do enfrentamento da epidemia HIV/aids no Brasil pela sociedade civil, e ilumina, assim, detalhes quase invisíveis desse processo histórico extremamente singular. Vale ressaltar que, embora ainda o particular, o inédito, o atípico sejam muitas vezes, de modo preconceituoso, pensados como temas que nada informam sobre a 'totalidade', cada vez mais os estudos que revelam minúcias de processos sociais têm sido objeto de análise, pois levam a perceber a diacronia e a sincronia nos processos sociais (Costa, 1995).

Além disso, outra especificidade da Casa Siloé, que é sua vinculação com a Igreja católica, permite uma análise em que se entrecruzam questões da aids, questões sociais e desenvolvimento das ações sociais da Igreja católica, oferecendo um panorama rico e ao mesmo tempo complexo. No que diz respeito à inserção de grupos religiosos em ações sociais, Burity (2002) destaca que aquilo que efetivamente sabemos sobre essas práticas e sua real contribuição é muito pouco; dessa forma, conforme o autor, "há um território em busca de uma cartografia" (p.15).

A história da Casa Siloé fornece também elementos para a discussão sobre o tema da proteção social, especialmente no que diz respeito ao papel do Estado e das organizações voluntárias - entendidas aqui como entidades cuja criação foi determinada pela decisão de um grupo de pessoas que deseja praticar ajuda mútua e prestar serviços a segmentos particulares da população. Do ponto de vista de uma macroanálise, isto é, de uma visão 'de fora' das organizações voluntárias, podemos considerar que a mobilização 
1 Este projeto de pesquisa foi analisado e aprovado pelo Comitê de Ética em Pesquisa do Instituto de Saúde, da

Secretaria de Estado da Saúde de São Paulo. Foi obtida permissão escrita do fundador da Casa Siloé para que seu nome constasse tanto na dissertação de Mestrado apresentada pela primeira autora como em futuras publicações. dessas organizações institui um arranjo plural ou misto de proteção social, em que a proeminência do Estado é suprimida, ficando este com o papel de 'animador' e financiador, quando necessário (Pereira, 2003). Assim, as instituições que promovem o voluntariado estariam substituindo o Estado no enfrentamento da questão social, principalmente no que tange a áreas fundamentais (educação, saúde, trabalho, assistência social e previdência social). Para Fagundes (dez. 2006), o apelo ao voluntariado e à solidariedade traz o risco de que a discussão sobre as políticas públicas sociais se dilua e de que o caráter universalizante dos direitos sociais, garantidos constitucionalmente, também se dissipe no discurso de que todos são responsáveis, o que, na prática, pode significar que ninguém é responsável. Para Montaño (2005), a resposta às necessidades sociais, ao deixar de ser responsabilidade do Estado e direito do cidadão, passa a ser uma 'opção' do voluntário que ajuda o próximo e não um 'direito' do portador de necessidade. O presente estudo tenta complementar essa macroanálise aqui delineada, ao oferecer uma microanálise que desvela o processo de construção e manutenção de uma dessas organizações voluntárias, permitindo, ainda que parcialmente - pois se refere a uma só organização -, uma visão 'de dentro'.

\section{Procedimentos metodológicos}

Para estudar a história da Casa Siloé utilizou-se a abordagem metodológica qualitativa, que envolve a análise de dados obtidos no contato direto do pesquisador com a situação estudada. Os estudos qualitativos enfatizam mais o processo do que o produto e preocupam-se em retratar a perspectiva dos sujeitos envolvidos na pesquisa (Lüdke, André, 1986; Minayo, 1999; Nogueira-Martins, Bógus, 2004).

Como estratégias para a coleta de dados, foram escolhidas a história oral (Meihy, 2002; Ferreira, Amado, 2002) e a análise documental (Alves-Mazzotti, Gewandsznadjer, 1998). A primeira foi escolhida porque permite reconstruir a história da instituição com base nos relatos daqueles que dela participaram em determinado período, mediante suas referências e também seu imaginário (Thompson, 1992). A análise documental foi utilizada por possibilitar a complementação, fundamentação e validação das informações obtidas nas entrevistas (Lüdke, André, 1986). ${ }^{1}$

Os entrevistados, isto é, os sujeitos da pesquisa, são informantes-chave que participaram ativamente na construção e no processo de desenvolvimento do trabalho da casa de apoio, com conhecimento íntimo e detalhado desse trabalho. Os informantes-chave foram: o presidente da instituição; dois coordenadores que atuaram na casa em momentos diferentes (coordenador 1, de 1994 a 
1997, e coordenador 2, de 1997 a 2003); um membro da diretoria da Sociedade Padre Constanzo Dalbésio (sociedade mantenedora da Casa Siloé), que representa a entidade desde 1994 e exerce, além das funções de membro da diretoria, trabalho voluntário na casa; uma assistente social voluntária que participou da organização formal da instituição em 1994 e atua voluntariamente na casa; um membro do Fórum de ONGs/aids do Estado de São Paulo; e um médico e uma psicóloga do serviço público estadual, que acompanharam o desenvolvimento da Casa e prestaram assistência às crianças.

As entrevistas foram realizadas com base em um roteiro, por meio do qual se estimulou o entrevistado a falar sobre a origem da instituição, a mobilização comunitária, o papel da casa de apoio, êxitos e dificuldades, o papel do Estado e perspectivas. O entrevistado tinha ampla liberdade para falar, podendo comentar e enfatizar aspectos que considerasse relevantes. As entrevistas foram gravadas e transcritas.

A análise documental permitiu a complementação das informações obtidas nas entrevistas. Os documentos consultados foram: Plano de Trabalho da Sociedade Padre Constanzo Dalbésio (SPCD), que forneceu dados relacionados a histórico da instituição, diretrizes do trabalho, organização e funcionamento da casa de apoio, capacidade de atendimento e recursos humanos, físicos e materiais; vídeos produzidos pela instituição ou por outras; prontuários das crianças, para levantamento estatístico do número de abrigadas, adotadas ou que retornaram à família, bem como do número de óbitos; documentos da Conferência Nacional dos Bispos do Brasil (CNBB); e livros e artigos sobre assuntos relacionados a aids, casas de apoio, ONGs e Igreja católica. O material obtido nas entrevistas e na análise documental levou à construção de categorias temáticas que recompõem a constituição e trajetória da Casa Siloé.

\section{Resultados e discussão}

As categorias temáticas são as seguintes: Igreja católica e aids; mobilização comunitária; a Casa Siloé, o Estado e a sociedade civil; avaliação e perspectivas do projeto.

Igreja católica e aids

Para abordar o histórico da Casa de Apoio Siloé, é necessário contextualizá-la no movimento religioso católico focando, particularmente, alguns fatos que consolidaram a Teologia da Libertação, movimento em que se insere o fundador da Casa.

Na América Latina, em 1955, com a criação do Conselho Episcopal Latino-americano (Celam), houve uma preocupação da Igreja católica em identificar os principais problemas enfrentados na 
evangelização do continente. Uma das metas a serem alcançadas era a da intervenção da Igreja na vida social, como uma alternativa aos radicalismos de esquerda e de direita existentes à época. O êxito comunista em Cuba, em 1959, fez que se agravassem as contradições internas da Igreja, provocando uma reorganização do clero e das lideranças, que se dividiram em dois grupos: os que renovaram o seu empenho no social e os que radicalizaram no anticomunismo (Santos, 2004).

No final da década de 1960, com as novas orientações do ecumenismo, a questão social passou a ocupar o centro das preocupações da Igreja. As resoluções do Concílio Ecumênico Vaticano II foram importantes para o grupo de religiosos, leigos e bispos que apostaram na reforma social como a terceira via, colocando-a acima do comunismo e do capitalismo. Em resposta aos desafios apresentados pelo Concílio foi aprovado, em 1965, o Plano de Pastoral de Conjunto da Igreja, conseqüência da necessidade de renovar estruturas dessa instituição religiosa. Uma nova teologia foi construída, tomando por base a realidade latino-americana, marcada pela concentração de riquezas e desigualdades sociais: a Teologia da Libertação. Um dos pressupostos básicos dessa teologia é a articulação entre leigos e religiosos a fim de produzir novas práticas pastorais, voltadas especialmente à realidade das periferias e das áreas rurais. Vale ressaltar que a Teologia da Libertação veio também ao encontro de dois desafios: a concorrência religiosa com o pentecostalismo e o afastamento de boa parte dos fiéis, que não encontravam motivação nas cerimônias litúrgicas (Costa, 1995; Burity, 2002; Santos, 2004; Silva, 2006).

As Comunidades Eclesiais de Base (CEBs) e as pastorais sociais se consolidaram por todo o Brasil ao longo da década de 1970, graças aos incentivos de padres, leigos e religiosas das paróquias localizadas nos bairros da periferia. Sua principal característica consistia em discutir os problemas sociais valendo-se da leitura do Evangelho e exigir do poder público respostas às questões do cotidiano dos cidadãos (Silva, 2006).

A epidemia de aids emergiu quando a Igreja católica vivia o pontificado de João Paulo II, que adotava posições claramente conservadoras, privilegiando os temas espirituais e disciplinares mais do que os problemas sociais (Aquino et al., 1999). Dessa forma, os religiosos católicos, os pentecostais, como também vários grupos da sociedade civil, primeiro trataram a aids como algo restrito ao mundo da moral, para depois acolhê-la como uma linha de atuação relevante e digna (Galvão, 1997b). Respostas baseadas nos princípios de fé e solidariedade da Igreja católica promoveram, por parte da Arquidiocese de São Paulo, em 1987, a criação do Projeto Esperança, que mesclava apoio legal, educação e atendimento a portadores do vírus e seus familiares. 
No entanto, foi nos anos 90, já na segunda década da epidemia, que as respostas religiosas tornaram-se mais presentes no Brasil. No caso da Igreja católica, a partir da vocação que d. Paulo Evaristo Arns denominou 'resposta samaritana' (Arns, 1990, p.77), que é a resposta cristã de amor e compaixão por aqueles afetados pela aids - pacientes, familiares, amigos e equipe prestadora de assistência -, começou a implementação das casas de apoio e o atendimento domiciliar para pessoas com HIV/aids. Ao mesmo tempo, campanhas religiosas como a campanha da fraternidade, da Igreja católica no Brasil, abordaram temas relacionados à problemática da aids.

Nas diretrizes para 2003-2006, a CNBB assumiu compromisso com o problema da aids, criando um Serviço de Prevenção do HIV e assistência aos soropositivos (CNBB, 2000). Em junho de 2000, bispos, padres, diáconos, religiosos e religiosas, agentes de pastorais e líderes de ONGs estiveram reunidos em Itaici, município de Indaiatuba, estado de São Paulo, com o objetivo de traçar estratégias para o enfrentamento da epidemia de aids. Esse encontro, promovido pela Comissão Nacional de DST/aids (CN-DST/aids), da Pastoral da Saúde, gerou a Carta de Itaici, na qual a Igreja católica do Brasil posicionou-se claramente a favor de atitudes em benefício dos menos favorecidos acometidos pela doença.

Em relação à assistência, a Igreja católica engajou-se na luta contra a aids por meio de diversas iniciativas, entre elas a implementação de algumas casas de apoio. O Catálogo de Organizações da Sociedade Civil HIV/aids 2001/2002 do Ministério da Saúde (Brasil, 2001/2002) aponta a existência, no município de São Paulo, de vinte casas de apoio para crianças portadoras do HIV/aids. Cinco delas são de iniciativa direta da Igreja católica: a Casa Vida I e II, da Arquidiocese de São Paulo; o Sítio Agar, de padres franciscanos; e a Casa Siloé e o Lar Suzanne, de iniciativa missionária.

Portanto, é no âmbito da iniciativa missionária que se insere o histórico da Casa Siloé. O fundador da instituição, padre Valeriano Paitoni, nasceu em 1948, em Pontevico (Brescia, Itália) e entrou no Instituto dos Missionários da Consolata em 1966 (Seminário de Varallo). Foi ordenado diácono em 1976 e padre, um ano depois. Chegou ao Brasil em 1978, estabelecendo-se na cidade de Cascavel (Paraná). Em 1984-1985, já em São Paulo, foi secretário da Animação Missionária Vocacional (SPCD, s.d.).

Padre Valeriano Paitoni engajou-se na luta contra a aids em 1988, como voluntário na casa de apoio Aliança Para a Vida (Alivi). Em 1991 fundou a Casa de Apoio Lar Betânia, para 12 portadores do HIV. Foi transferido em 1993 para a Paróquia Nossa Senhora de Fátima, no bairro Imirim, zona norte de São Paulo. Em junho de 1994 fundou a Sociedade Padre Costanzo Dalbésio (SPCD, 1998), entidade filantrópica cujo objetivo era implementar serviços de assistência social na comunidade e que tornou-se a mantenedora das 
obras sociais da Paróquia Nossa Senhora de Fátima. Em outubro do mesmo ano fundou a Casa de Apoio Siloé, para crianças portadoras do HIV/aids.

\section{A mobilização comunitária}

Para o início do trabalho, o fundador da Casa Siloé refere que privilegiou o contato com a comunidade:

No começo, o trabalho foi na comunidade, eu esqueci os superiores ... porque eu sabia que se a gente entrasse em discussão, eles iam tentar frear esse tipo de iniciativa. Foi por isso que eu trabalhei muito com o Conselho Pastoral da paróquia. O Conselho aceitou e levamos à frente ... Depois, apresentamos, aos superiores o trabalho já começado, um fato concreto que acontecia na comunidade paroquial. (padre Valeriano)

Apesar de alguma resistência por parte de seus superiores, padre Valeriano tinha seus objetivos fundamentados nas Diretrizes Gerais da Ação Pastoral da Igreja no Brasil (CNBB, 1992), segundo as quais a vivência comunitária deve multiplicar e diversificar, especialmente no meio urbano, comunidades eclesiais que suscitem, eduquem e apóiem a experiência de fé a partir da comunhão fraterna:

A construção foi uma obra coletiva, com a participação de várias pessoas. Aos sábados aumentava muito o número de pessoas da comunidade, misturando massa, puxando tijolo, limpando o chão, colaborando com os operários que eram remunerados. Nos fins de semana a comunidade estava ali apoiando: o grupo de jovens da paróquia, casais, famílias inteiras se doando. (coordenador 1)

Vale ressaltar alguns aspectos relativos à mobilização comunitária, pois ela está ligada ao complexo e instigante tema do voluntariado. Alguns estudos mostram interessantes ângulos da questão. Em estudo da trajetória da Cruzada Pró-Infância, por exemplo, Mott (2001) questiona a afirmativa corrente de que "a atividade benemerente foi sempre um subterfúgio para aquelas mulheres deixarem o lar e combaterem uma existência inútil" (p.233). Selli e Garrafa (2005), por sua vez, detectaram três motivações possíveis para o engajamento em ações voluntárias:

- motivações pessoais relacionadas à vida do voluntário e que têm como centro de interesse a busca da realização pessoal;

- motivações decorrentes da crença professada, em que a motivação é fecundada pelos preceitos que sustentam sua fé;

- motivações despertadas por um sentimento relacionado ao bem do outro. 
Os autores formulam o conceito de voluntariado orgânico, entendido como "participação politizada, comprometida, ativa e beneficente das pessoas que desenvolvem o serviço voluntário na construção das condições necessárias à democratização efetiva do Estado" (Selli, Garrafa, 2005, p.474). Afirmam, ainda, que a prática voluntária orgânica revela-se pela capacidade daqueles que atuam como agentes que desencadeiam consciente e criticamente a participação das pessoas em questões que envolvem as problemáticas sociais. Assim, sob esse ponto de vista, podemos considerar o fundador da Casa Siloé como um desses agentes, pois conseguiu estimular um grande número de pessoas para a causa das crianças com HIV/aids, enfrentando preconceitos e resistências.

Voluntariado e solidariedade são expressões que costumam caminhar juntas. O termo solidariedade vem sendo objeto de discussões e reflexões por parte de muitos autores. Em meados dos anos 90 essa palavra ganhou destaque como catalisador social. A retórica da solidariedade (Rorty, 1992; Góis, 2004b), de origem cristã, transformou-se nesse período em instrumento de mobilização para o enfrentamento da crise social, econômica e civilizatória, já que antigos códigos e linguagens não mais eram suficientes para o enfrentamento dos graves e complexos problemas sociais. Na análise da retórica da solidariedade, reputamos fundamental a idéia de Rorty (1992), de que a solidariedade precisa ser aprendida, construída; assim, todos têm responsabilidade na manutenção dessa construção. Selli e Garrafa (2005) apresentam a noção de solidariedade crítica, em que a adjetivação diz respeito à capacidade de o agente discernir, ou seja, possuir critérios capazes de ajudá-lo a discriminar a dimensão social e política que estão indissociavelmente presentes na relação solidária. Já para Montaño (2005), há duas formas de entender a solidariedade: como opção e como direito. No primeiro acaso, o sujeito da ação solidária deve apelar para a boa vontade, disponibilidade e sensibilidade de outrem, e deve se resignar a aceitar o que vier, como vier. No segundo caso, a obrigatoriedade da ação solidária é constitutiva do direito social, e o sujeito da ação solidária tem o direito de obtê-la; neste caso, o garantidor e executor da atividade solidária como obrigação de todos e da prestação de socorro como direito de todos é o Estado. Para o autor, a verdadeira questão é o confronto entre essas duas visões de solidariedade, e não a falsa contraposição entre defensores e opositores da solidariedade.

Assim, levando em conta as considerações anteriores, no projeto Casa Siloé a solidariedade está presente como opção e se apresenta como solidariedade crítica:

O Estado é o responsável em primeiro lugar ... Agora, acontece o seguinte: existe um Estado de direito e um Estado de fato. Infeliz- 
2 Siloé é um nome bíblico, dado a um canal que fornecia água à cidade de Jerusalém. A água desse canal era recolhida em um tanque chamado Piscina de Siloé, que, no tempo de Jesus, era circundado por uma colunata construída por Herodes Magno.

\footnotetext{
3 O dízimo

corresponde à décima parte do salário do fiel e é entregue à Igreja.
}

mente, é o Estado de fato que a gente constata todos os dias, nos jornais, pela mídia, pela nossa realidade, esse Estado real. $\mathrm{O}$ ideal é que o Estado atenda essas pessoas, mas elas estão precisando disso agora, e se formos pressionar o Estado, isso pode levar tempo. Então, nesse sentido, projetos como os das casas de apoio têm um papel importante, por estarem dando respaldo e apoio imediatos. (coordenador 1)

\section{A Casa Siloé, o Estado e a sociedade civil}

Em outubro de 1994, a Casa Siloé ${ }^{2}$ foi inaugurada com uma missa celebrada pelo então arcebispo da Região de Santana, d. Joel Ivo Cataplan. Sua presença teve o papel de reforçar a necessidade de a Igreja estar à frente da situação da aids em uma ação missionária, acolhendo as vítimas da doença. D. Joel autorizou que parte da arrecadação proveniente de doações dos fiéis, nas missas pelo dízimo ${ }^{3}$, fosse destinada à Casa de Apoio.

Para organizar a instituição, os iniciadores do projeto contaram com a ajuda de alguns profissionais que pertenciam à comunidade: uma pedagoga, uma assistente social, um advogado, uma farmacêutica e outras pessoas que colaboraram em vários aspectos do trabalho. Esses profissionais empenharam-se na organização de cursos básicos de orientação, para que as pessoas envolvidas no projeto tomassem conhecimento tanto do trabalho que seria desenvolvido quanto da problemática da aids. Tiveram apoio de médicos do Instituto de Infectologia Emílio Ribas e de enfermeiros e nutricionistas do Serviço Nacional do Comércio (Senac), que vieram à comunidade fazer palestras introdutórias e orientadoras, em caráter voluntário.

Uma das propostas iniciais para a Casa Siloé era a de que ela seria estruturada como uma uma família, porque até então, no movimento da aids, as casas de apoio funcionavam como clínicas: "eram casas de repouso para acolher as pessoas que estavam sem ter onde morar ... como se fosse um depósito. [O padre Valeriano disse:] 'Esta casa não vai ser um depósito de pessoas, nem uma clínica, vai ser uma família'. Então, a casa começou a crescer com a idéia de família" (coordenador 1).

A proposta era, portanto, de atenção humanizada às crianças, isto é, atenção que levasse em conta suas características como seres humanos (sentimentos, emoções, desejos) e não somente os aspectos biomédicos. A premissa era que a experiência individual do adoecer é vivida de modo particular e único, constituindo-se comumente em momento de desordem física, subjetiva e contextual. Além disso, os estados de saúde e doença não são situações independentes ou isoladas, mas sim parte de um continuum integrado entre saúde/doença/corpo (Chammé, 2002; Góis, 2004b; Mandú, 
4 Desde a sua fundação, a Casa Siloé abrigou 43 crianças. No período analisado, 12 foram adotadas, nove delas soronegativas e três soropositivas; dez retornaram às suas famílias, sendo oito crianças soronegativas e duas soropositivas; quatro foram transferidas para outras instituições; e 14 continuam abrigadas. Houve três óbitos.
2004; Nogueira-Martins, 2006). As primeiras crianças foram encaminhadas pelo Serviço Social do Instituto de Infectologia Emílio Ribas. A chegada da primeira criança trouxe muita ansiedade aos voluntários, por ser muito frágil, com problemas cardíacos. Surgiram então as primeiras dificuldades, originadas do despreparo e desconhecimento da doença: "Foi aí que eu conheci a dra. M., que me orientava por telefone. Um dia fui levar C. na consulta, e ela me orientou sobre como proceder quando a C. não estivesse bem, como avaliar se era necessário ou não levá-la ao pronto-socorro. Aí foi que começamos um aprendizado em relação à aids" (assistente social).

Tiveram papel relevante na orientação de voluntários e funcionários as equipes de médicos, enfermeiros, assistentes sociais, psicólogos, nutricionistas e farmacêuticos do Instituto de Infectologia Emilio Ribas, do Instituto da Criança do Hospital das Clínicas da Faculdade de Medicina da Universidade de São Paulo, do Hospital Mandaqui e dos Centros de Referência.

Após contato de membros da Casa Siloé com outros hospitais e Varas de Infância da Zona Norte, outras crianças vieram e foram acolhidas": "Ninguém tinha experiência em como agir, como montar uma casa de apoio para crianças; era tudo uma experiência nova. Tínhamos que dar respostas aos problemas quando eles surgiam. Foi muito empolgante, porque era tudo novidade ... Requeria ações imediatas ... Então, fizemos a experiência caminhando..." (padre Valeriano).

Embora a orientação fosse o cuidado integral da criança, a prioridade inicial foi a medicação, que devia ser corretamente administrada. A alimentação também era importante, porque a maioria das crianças chegava debilitada; além disso, eram fundamentais o cuidado com a higiene das crianças e a limpeza da casa.

A procura por informações sobre as crianças também fazia parte da rotina da casa. Os coordenadores, com a ajuda de voluntários, faziam busca nos serviços de saúde por onde as crianças haviam passado, para obter carteiras de vacinação e relatórios médicos, de psicólogos e de outros profissionais. A organização dessas informações fez-se necessária, e foram montados cadernos e pastas que continham dados pessoais e dados sobre a saúde de cada criança: doenças anteriores, mudanças de medicação, resultados de exames, comunicados dos/aos médicos ou outros profissionais de saúde. Também da necessidade de organização do trabalho voluntário surgiu a demanda por capacitação e criação de rotinas, para o qual funcionários foram contratados. A chegada desses profissionais facilitou a organização do serviço e garantiu um vínculo entre os diversos voluntários.

Muitos comentários dos entrevistados referem-se aos recursos oficiais para o atendimento das crianças em hospitais e em unidades de saúde: 
Exames mais apurados, fenotipagem e genotipagem... tinha que entrar no Ministério Público para conseguir. Agora está liberado, mas você tem que atender pré-requisitos. Você é avaliado para saber se pode fazer ou não. Precisaria ter mais Centros de Referência, um lugar onde você encontraria o que precisa. Falta estrutura... Eu acho que é a falta de especialistas. (coordenador 2)

Com relação a especialistas como oftalmologistas, psicólogos, fonoaudiólogos e fisioterapeutas, apesar de estarem disponíveis nas Unidades Básicas e Centros de Referência (CR), o atendimento é demorado, pois a demanda é muito grande. Em geral a espera por uma vaga dura meses. Exames específicos como tomografia ou mesmo exames clínicos como dosagem de hormônios não são oferecidos a contento, porque o número de exames estabelecido pelo Sistema Único de Saúde (SUS) para cada unidade não é suficiente. Porém ressalta-se a importância do trabalho conjunto entre sociedade civil e Estado:

A questão da luta contra a aids aqui no Brasil tem uma história muito bonita porque as entidades não-governamentais souberam fazer desde o começo uma luta mundial ... Claro que o Estado tem tantos outros interesses que às vezes não batem com os interesses humanos das ONGs, mas no caso da aids foi uma luta muito bonita, tanto que se nós hoje, no Brasil, temos esse trabalho a respeito da aids reconhecido mundialmente, é porque as ONGs e as pessoas que trabalharam no governo acreditaram muito e tiveram muito boa vontade para dar uma resposta concreta ao problema. (padre Valeriano)

Em alguns momentos, a ajuda do governo trouxe benefícios para a instituição, como a realização de um vídeo pelo Programa Nacional de DST e Aids e pela Unesco, juntamente com a Sociedade Padre Constanzo Dalbésio, em 2000. O vídeo Em defesa da vida são outros 500 questiona a postura da Igreja católica perante os desafios da sociedade contemporânea. A Comissão Nacional de DST/aids, por duas vezes, concedeu ajuda financeira a projetos da Sociedade Padre Constanzo Dalbesio. Um deles, em 2001, beneficiou-a na área de desenvolvimento institucional, e em 2003 uma parcela do dinheiro recebido da Fundação Bill Gates pela CN-DST/aids, como reconhecimento da qualidade do Programa Brasileiro de Combate à Aids, foi repassado para a Casa Siloé.

A necessidade de entrosamento da instituição com as escolas surgiu em 1996. A mídia, na época, propagava as dificuldades que pais de crianças soropositivas encontravam para colocar seus filhos na escolas públicas e particulares. O caso emblemático dessa situação ocorrera em maio de 1992 com a menina Sheila Cortopassi, com cinco anos e soropositiva, que teve sua matrícula recusada 
5 Em 2004, nove crianças estudavam em colégios missionários católicos, três estavam em escolas da rede pública e uma freqüentava uma escola especial para deficientes. por uma escola de São Paulo: “Este acontecimento, que ficou conhecido como 'caso Sheila', motivou um sério debate sobre os direitos das crianças soropositivas, sobretudo o seu direito de freqüentar a escola" (Galvão, 1997a, p.122).

Ao lado da Casa Siloé havia um colégio de freiras que também eram missionárias da Irmandade Consolata. O pedido para que acolhessem as crianças soropositivas na escola foi fundamentado no fato de que as irmãs, como missionárias, não podiam se omitir diante dessa situação, e elas aceitaram o desafio. As maiores dificuldades ocorreram com os professores, mas um trabalho de conscientização foi realizado junto a eles, bem como a pais e alunos:

Os pais não tiveram reação nem positiva nem negativa: ficaram 'em cima do muro', aguardando o que aconteceria. Da parte dos professores é que surgiram questionamentos que eu não esperava: "como é que transmite [a doença]?", "se eles se machucarem, o que vamos fazer?". Até entendo a preocupação, mas eles revelaram uma certa resistência, velada... (padre Valeriano)

Devido ao problema de inserção escolar ${ }^{5}$ enfrentado pelas crianças portadoras de HIV/aids em todo o Brasil, a Casa Siloé, em parceria com o Grupo de Incentivo à Vida (GIV), produziu um material pedagógico para ser utilizado nas escolas, com o título Daniele Letícia: falando sobre aids. Elaborado por duas psicólogas, duas pedagogas e um filósofo, o livro é fruto da experiência dos autores na área e baseado em literatura específica e entrevistas feitas com crianças soropositivas, soronegativas e filhas de portadores do vírus. Narra a história de crianças que encontram na escola uma colega portadora do HIV/aids, e tal contexto permite a reflexão sobre a informação como meio para acabar com o preconceito e tornar as pessoas mais solidárias, no convívio entre soropositivos e soronegativos.

Daniel e Letícia praticamente foi a primeira literatura que apresentamos como material didático a ser utilizado nas escolas para a conscientização de que uma criança portadora do HIV pode viver normalmente junto com os outros, sem problema nenhum. Tratava-se de conscientizar a sociedade de que aquela era uma realidade sobre a qual não podíamos fechar os olhos e que devíamos enfrentar, desde a educação nas escolas. E foi muito bem aceita, o Ministério [da Saúde] deu o aval deles. (padre Valeriano)

\section{A avaliação e as perspectivas do projeto}

Os entrevistados foram instados a fazer uma avaliação do projeto com base nos êxitos e nas dificuldades do trabalho, como também a tecer considerações sobre as perspectivas da Casa. Os ele- 
mentos considerados exitosos referem-se a: estrutura material e social decorrente da institucionalização e da participação comunitária na forma de adoção e retorno à família; melhora clínica das crianças, decorrente do uso adequado de anti-retrovirais, o que contribui com o trabalho dos profissionais de saúde; crescimento da expectativa de vida das crianças, com a conseqüente elaboração de projetos futuros, tais como relacionamentos afetivos e trajetória profissional.

[As crianças] tinham, na casa, condições materiais mínimas para viverem melhor: cama seca, comida preparada, orientação de medicação, suporte clínico. As crianças iam às consultas nos dias marcados, tomavam os remédios corretamente. Aliás, esse era um dos motivos para os hospitais encaminharem as crianças para as casas de apoio. (coordenador 1)

A partir da implementação da terapia anti-retroviral (ARV) para o tratamento da infecção pelo HIV/aids, a partir de 1996, não só houve uma diminuição significativa do número de mortes, como também reduziram-se as chamadas doenças oportunistas, melhorando portanto a sobrevida e a qualidade de vida dos portadores. Na perspectiva das crianças, essa melhoria tem significado a possibilidade de ter vida 'normal', chegar à adolescência e pensar em desenvolvimento e futuro. $O$ fundador da Casa Siloé percebe como êxito a maleabilidade da instituição perante essas alterações:

Uma coisa marcante na caminhada que fizemos até agora foi ter visto essas crianças vencerem, porque quando nós abrimos a casa, os médicos nos falavam ... que a criança que tinha o vírus não teria mais de seis, sete, oito anos de vida, se fosse bem cuidada. Então nós acolhíamos essas crianças, mas com a perspectiva de que a perderíamos, dia ou outro. Ver que essas crianças lutaram e alcançaram um tratamento para prolongar as suas vidas, quem sabe até quando ... Acho que um grande momento foi quando começaram a tomar esse coquetel e vimos que ele estava funcionando, não só nos adultos mas também nas crianças. (padre Valeriano)

Assim, apesar de ter se estruturado inicialmente para acolher crianças com pouca expectativa de vida, a instituição adaptou-se às mudanças do perfil epidemiológico da doença transcorridas nos últimos anos. Manteve-se atualizada com relação não só a medicamentos e conhecimento da evolução da doença, com também às necessidades clínicas das crianças, reivindicando mais especialidades para atendê-las e melhor estruturação dos Centros de Referência.

O êxito realmente é propiciar a vida, com todas as dificuldades, com todas as dores, com todas as situações tão complicadas do 
viver. Ainda assim se restabelece a vida, porque se não existisse a casa de apoio, muitos e muitos já teriam nos deixado, em virtude da situação de pobreza, miséria, falta de amor; muitos já teriam partido. O maior êxito é o resgate do dom da vida. (assistente social)

As primeiras adoções mediadas pela Casa Siloé foram de difícil concretização, devido à inexperiência. As instituições jurídicas, Vara de Infância e Juventude, Conselhos Tutelares e Fóruns, freqüentemente solicitavam relatórios sociais das crianças. Havia um advogado que colaborava voluntariamente, e posteriormente a coordenação da casa passou a realizar esses processos, o que foi considerado um êxito institucional:

Crianças que puderam se inserir em famílias, crianças que puderam ser adotadas, como é o caso da P., do E.; crianças que estão na escola, aprendendo música; famílias que estão dando amor, estrutura - Será que não é êxito, será que não valeu? Outro êxito é a gente estar convivendo com essa meninada que a gente viu aí, que tinha cinco, seis anos, como o S. Um fala de namorada, outro de mercado de trabalho: "eu quero fazer isto, fazer aqui$1 \mathrm{l}^{\prime \prime} ;$... "eu quero ser engenheiro", essas conquistas que eles estão almejando... (membro da diretoria da instituição)

Quanto às dificuldades, as mais intensamente referidas pelos entrevistados foram a falta de informação sobre as crianças e a falta de capacitação para os voluntários. Em relação a estes últimos, a quantidade foi considerada expressiva, mas o que dificultava o bom desenvolvimento do trabalho era a alta rotatividade.

Quando a Casa começou a operar, uma das maiores dificuldades do voluntariado residia nas dúvidas quanto a sua atuação na instituição. Alguns voluntários queriam ficar apenas com as crianças,

6 Em 2004, a Casa Siloé possuía seis funcionários - uma coordenadora, uma cozinheira, uma professora e três funcionárias para serviços gerais -, contando com o suporte de aproximadamente cem voluntários, que auxiliavam nos serviços de lavanderia, cozinha e limpeza e exerciam, também, as funções de babás, motoristas e acompanhantes hospitalares. apesar dos diversos afazeres da casa, o que demandou um trabalho de conscientização por parte da coordenação. ${ }^{6}$

Outra dificuldade apontada diz respeito ao resgate de valores perdidos pelas crianças, uma vez que, oriundas de famílias carentes, carregavam uma bagagem muito negativa de experiência humana e familiar:

Uma grande dificuldade nossa era restituir a eles, através da ajuda de psicólogos, da experiência humana de voluntários e funcionários, de princípios religiosos ... aquilo que a gente poderia chamar de dignidade humana e valores com os quais eles pudessem ter um futuro mais garantido, mais bonito, em termos humanos. (padre Valeriano)

Percebeu-se também freqüentemente, entre os entrevistados, uma ansiedade em relação à falta de um projeto psicopedagógico que 
orientasse o cuidado com as crianças e pudesse proporcionar uma vida melhor para elas. A casa estruturou-se sob uma perspectiva de 'família' e seguiu resolvendo os problemas conforme eles iam surgindo. Com o aumento de perspectiva de vida das crianças soropositivas, porém, resolver dificuldades 'domesticamente' parece não ser mais a melhor estratégia. As crianças trazem consigo questões de natureza variada, porque passaram por outras instituições, vivenciaram muitas faltas, perdas e traumas (perda de pais e amigos, internações, revelação do diagnóstico). Enfim, enfrentaram várias situações penosas e, na maior parte das vezes, sem apoio de profissionais como psicólogos e pedagogos.

Outra dificuldade apontada, esta concernente à saúde pública, diz respeito à postura e às diretrizes da Igreja católica:

E agora nós estamos enfrentando a questão de que esses adolescentes estão entrando na juventude, quase adultos, e surge a grande problemática da afetividade, do namoro e da prevenção ... Isso é uma grande dificuldade que a gente encontra com as autoridades eclesiais. Como Igreja, temos o que chamamos de valores evangélicos, que são indiscutíveis: a fidelidade, a castidade, e assim por diante. Porém isso não é suficiente, porque esses valores evangélicos nós adquirimos ao longo da nossa vida ... A Igreja, oficialmente, não admite o uso do preservativo; ela fala mais desses valores evangélicos. Só que eu acho que a Igreja oficial ainda não conseguiu entender e distinguir entre aquele que é um caminho religioso e o que é uma resposta à saúde pública. (padre Valeriano)

A posição oficial do Vaticano é proibir aos católicos o uso de qualquer contraceptivo, incluindo camisinhas, em qualquer circunstância, mesmo para evitar a transmissão do vírus HIV entre parceiros casados. A Igreja prega que a abstinência sexual e a fidelidade são as melhores maneiras de combater a doença. No entanto, sabese que tais estratégias são inadequadas como política de saúde pública para a prevenção do HIV e outras doenças sexualmente transmissíveis (DST). Sabe-se, também, que embora a crítica ao uso de preservativos venha do Vaticano, nem toda a Igreja católica do Brasil a difunde. Prova disso foi a posição da reunião de cúpula do CNBB em 2000, em Itaici, a respeito do preservativo, que foi considerado, "dos males, o menor" (Brasil, 2003).

Sobre as perspectivas da instituição, houve unanimidade entre os entrevistados: a principal perspectiva do trabalho de uma casa de apoio é a reinserção familiar e social das crianças. Para alguns, em futuro muito próximo as casas de apoio serão substituídas por casas de passagem, que atenderão crianças em fases de muita dificuldade de saúde ou com problemas familiares. Surgiram propostas de apoio à família nos níveis econômico e social, em vez de manter 
a criança na casa de apoio: "Eu acho que uma casa de apoio é uma bênção para uma criança que não tem para onde ir, melhor que um orfanato ou coisa assim. Eu acho que, a longo prazo, acabar com as casas de apoio ... O ideal seria reintegrar à sociedade. Por isso que eu falo em longo prazo: é um trabalho muito demorado, muito difícil" (coordenador 2).

Uma vez que abriga as crianças e atende às suas necessidades básicas, um outro problema surge para a Casa de Apoio: o distanciamento entre a criança e sua família. Como esta recorre à casa de apoio por não reunir condições mínimas para cuidar da criança, acaba por delegar à instituição a responsabilidade pela educação de seus filhos. O retorno das crianças às suas famílias reveste-se de vários problemas, pois a freqüente desintegração do núcleo familiar deve-se não somente à aids mas também a pobreza, vida em favela, migração, consumo e tráfico de drogas, morte violenta e incapacidade de cuidar dos filhos (Abadia-Barrero, 2002): "A casa de apoio é um mal necessário. Bom seria se elas não existissem, e as famílias tivessem consciência que o lugar dessas crianças é nas próprias famílias. Mas já que eles não têm, a casa de apoio passa a ser esse mal necessário que vem suprir aquilo que é da responsabilidade da família" (membro da diretoria da Instituição).

De acordo com o fundador da Casa Siloé, pensar em perspectivas implica dar respostas concretas, porque as crianças se transformaram em jovens e vão se reinserir na sociedade já no mundo dos adultos, o que traz à baila questões como emprego, sexualidade, namoro e composição de uma família. A instituição deve estar ao lado desses jovens quando eles necessitarem de ajuda.

\section{Considerações finais}

Por meio do histórico da Casa Siloé, podemos refletir sobre os vários papéis das casas de apoio. Um deles seria o de que, como conseqüência de seu existir, elas transformam as crianças com HIV/ aids em 'sujeitos falantes', audíveis e reconhecíveis socialmente, ampliando o 'mundo comum' das pessoas ao abrir-lhes um leque de problemas, dramas e histórias que singularizam essa forma de existência; permitindo o surgimento de outras 'descrições do mundo', isto é, descrições alternativas àquelas já existentes; trazendo algo novo para a paisagem cotidiana da população (Rorty, 1992; Telles, 1997).

As casas de apoio contribuem também para a redefinição das práticas assistenciais do sistema de proteção social brasileiro, pois contrapõem às antigas formas de filantropia, assistencialistas e paternalistas - que correspondem a uma atitude mais passiva na formação e gestão de redes de articulação social-, experiências mais afinadas com o discurso da cidadania e da solidariedade (Costa, 
1995; Burity, 2002). A trajetória da Casa Siloé revela a instituição 'casa de apoio' como um lugar de fronteira, situado entre o hospital e a família, entre o orfanato e a família, entre as instituições educacionais e as instituições médicas. Esse lugar de fronteira tem uma nova identidade, pois agrega funcionários e voluntários com diferentes formações.

Quanto ao voluntariado, na Casa Siloé, assim como em outras instituições, a situação se coloca como uma moeda de duas faces: a solidariedade e participação dos voluntários são essenciais para a continuidade dos trabalhos, porém, por terem motivações diversas para a atividade que desenvolvem, como as descritas por Selli e Garrafa (2005), tendem a adotar diferentes atitudes para com as crianças. Em casas de apoio, a troca afetiva parece fundamental, não só no cuidado da criança e na relação emocional de mãe/pai substituta(o) e filha/filho substituta(o), como também na retribuição moral - idéia baseada na religiosidade - pelas boas atitudes. O problema é que essa bondade permite desculpar e justificar os desacertos (Abadia-Barrero, 2002), impedindo muitas vezes que as pessoas aprendam e se modifiquem. Assim, a existência de um projeto psicopedagógico institucional, apontado pelos entrevistados, é de grande importância tanto para essa instituição como para todas as que trabalham com voluntários. Além disso, não se pode esquecer a necessidade de aprimoramento constante do voluntariado na direção da solidariedade crítica, que leva a uma prática que supõe sujeitos engajados, politizados e comprometidos com a causa social.

O aumento da perspectiva de vida das crianças, graças à terapia ARV, tem levado a modificações nas casas de apoio para crianças, pois estas têm que enfrentar problemas relativos a sexualidade, trabalho, independência e autonomia, característicos dos jovens. Um desafio para essas casas é preparar os adolescentes para serem pessoas autônomas e enfrentarem o estigma e o preconceito. O estigma tem sido identificado, no contexto da aids, como um aspecto marcante. Há o estigma 'sentido', internalizado pelo indivíduo, e o 'efetivado', que a sociedade constrói efetivamente. Ambos têm grande impacto na saúde e na qualidade de vida das pessoas envolvidas (Maluwa, Aggleton, Parker, 2002). Portanto, preparar esses adolescentes para a vida exige um esforço pautado por um preparo psicopedagógico dos que com eles lidam.

A trajetória da Casa Siloé mostra claramente que, apesar das dificuldades e dos conflitos, foi possível construir na comunidade do Imirim, em São Paulo, uma rede de solidariedade que tem se mantido nesses dez anos de atividade e que proporciona às crianças - portadoras, doentes ou não, órfãs ou não, mas, de alguma forma, excluídas de suas origens - melhor qualidade de vida, acompanhamento clínico adequado, moradia digna e convivência sau- 
dável. Assim, retomando a questão do papel do Estado no que tange à proteção social, ressaltamos, com Fagundes (dez. 2006), que o voluntariado e a solidariedade devem ser considerados importantes valores morais a serem resgatados, porém as políticas sociais responsáveis por dar conta das desigualdades sociais não devem ser baseadas exclusivamente nesses valores. Desejável seria caminhar para um modelo constituído por uma rede universal de proteção social que explicitasse o dever do Estado na garantia de direitos sociais (Soares, 2005).

\section{REFERÊNCIAS BIBLIOGRÁFICAS}

Abadia-Barrero, César Ernesto 2002

Alves-Mazzotti, AldaJudith; Gewandsznajder, Fernando 1998

Aquino, Rubim Santos Leão et al. 1999

Arns, Paulo Evaristo 1990

Brasil 2003

Brasil $2001 / 2002$

Brasil 2001

Burity, Joanildo A. 2002

Chammé, Sebastião Jorge 2002

CNBB 2000

CNBB

1992
Crianças vivendo com HIV e casas de apoio em São Paulo: cultura, experiências e contexto domiciliar. Interface - Comunicação, Saúde, Educação, Botucatu, v.6, n.11, p.55-70.

O método nas ciências naturais e sociais: pesquisa quantitativa e qualitativa. São Paulo: Pioneira.

História das sociedades: das sociedades modernas às sociedades atuais. 37.ed. Rio de Janeiro: Record.

Enfrentando a aids em São Paulo. Instituto de Estudos da Religião. Igrejas e aids: perspectivas bíblicas e pastorais. Rio de Janeiro: Iser.

Ministério da Saúde. Programa Nacional de DST/Aids. Carta aberta: posição do Programa Nacional de DST e Aids frente à proibição de divulgação de campanha da Sociedade Civil. Brasília: Ministério da Saúde.

Ministério da Saúde. Catálogo de organizações da sociedade civil HIV/aids. Brasília: Ministério da Saúde.

Ministério da Saúde. Norma conjunta do Centro de Referência e Treinamento em DST/Aids (CRT) e Centro de Vigilância Sanitária (CVE), artigo 19. In: Ministério da Saúde. Definição de Casa de Apoio. Brasília: MS.

Redes sociais e o lugar da religião no enfrentamento de situações de pobreza: um acercamento preliminar. Disponível em: http://www.fundai.gov.br/geral/ textos\%20online/ciencia\%20politica/jburity08.pdf.

Acesso em: 20 maio 2005.

Corpo e saúde: inclusão e exclusão social.

Saúde e sociedade, São Paulo, v.11, n.2, p.7-13.

Conferência Nacional dos Bispos do Brasil. Diretrizes gerais da ação pastoral da Igreja no Brasil: 2003-2006. São Paulo: Paulinas.

(Documentos da CNBB, 71).

Conferência Nacional dos Bispos do Brasil. Diretrizes gerais da ação pastoral da Igreja no Brasil: 1991-1994. São Paulo: Paulinas.

(Documentos da CNBB, 45). 
Costa, Suely Gomes da 1995

Fagundes, Helenara Silveira dez. 2006

Ferreira, Marieta de Moraes; Amado, Janaína 2002

Galvão, Jane $1997 a$

Galvão, Jane $1997 b$

Góis, João Bosco Hora 2004a

Góis, João Bosco Hora 2004b

Lüdke, Menga; André, Marli Eliza

1986

Maluwa, Mirima;

Aggleton, Peter; Parker, Richard

2002

Mandú, Edir Nei

Teixeira

2004

Marques, Maria

Cristina da Costa

2002

Meihy, José Carlos

Sebe Bom

2002

Minayo, Maria Cecília de Souza

1999

Montaño, Carlos 2005

Mott, Maria Lúcia 2001

Nichiata, Lucia Yasuko Izumi
Signos em transformação: a dialética de uma cultura profissional. São Paulo: Cortez.

O voluntariado, a solidariedade e as políticas sociais. Revista Virtual Textos $\mathcal{E}$ Contextos, Porto Alegre, ano 5, n.6. Disponível em: http:// revistaseletronicas.pucrs.br/ojs/index.php/fass/article/viewFile/1029/809. Acesso em: 9 out. 2007

Usos e abusos da história oral.

5.ed. Rio de Janeiro: Ed. Fundação Getúlio Vargas.

As respostas das organizações não governamentais brasileiras frente à epidemia de HIV/Aids. In: Parker, Richard. Políticas, instituições e aids: enfrentando a aids no Brasil. Rio de Janeiro: Associação Brasileira Interdisciplinar de Aids. p.69-108.

As respostas religiosas frente à epidemia de HIV/aids no Brasil. In: Parker, Richard. Políticas, instituições e aids: enfrentando a aids no Brasil. Rio de Janeiro: Associação Brasileira Interdisciplinar de Aids. p.109-134.

Aids. In: Silva, Francisco Carlos Teixeira (Org.). Enciclopédia das guerras e revoluções do século $X X$ : as grandes transformações do mundo contemporâneo. Rio de Janeiro: Elsevier. p.21-23.

Rede de solidariedade nos anos 90. In: Silva, Francisco Carlos Teixeira (Org.). Enciclopédia das guerras e revoluções do século XX: as grandes transformações do mundo contemporâneo. Rio de Janeiro: Elsevier. p.741-743.

Pesquisa em educação: abordagens qualitativas.

São Paulo: Ed. Pedagógica e Universitária.

HIV and aids: related stigma, discrimination and human rights: a critical overview. Health and human rights, Boston, v.6, n.1, p.3-20.

Intersubjetividade na qualificação do cuidado em saúde.

Revista Latino-Americana de Enfermagem, Ribeirão Preto, v.12, n.4, p.665-675.

Saúde e poder: a emergência política da aids/HIV no Brasil.

História, ciências, saúde - Manguinhos, Rio de Janeiro, v.9, supl., p.41-65.

Manual de história oral.

4.ed. São Paulo: Loyola.

Pesquisa social: teoria, método e criatividade.

12.ed. Petrópolis: Vozes.

Terceiro setor e questão social: crítica ao padrão emergente de intervenção social. São Paulo: Cortez.

Maternalismo, políticas públicas e benemerência no Brasil (1930-1945). Cadernos Pagu, Campinas, v.16, p.199-234.

A epidemia de aids infantil e os sistemas de informação: limites e possibilidades da intervenção em Saúde Coletiva na cidade de São Paulo. Tese (Doutorado) - Universidade de São Paulo, São Paulo. 
Nogueira-Martins, Maria Cezira Fantini 2006

Nogueira-Martins, Maria Cezira Fantini; Bógus, Cláudia Maria 2004

Pereira, Potyara

Amazoneida 2003

Rorty, Richard 1992

Sanches, Renate Meyer 1999

Santos, Patrícia Teixeira 2004

Selli, Lucilda; Garrafa, Volnei 2005

Silva, Claudia Neves da 2006

Soares, Laura Tavares 2005

SPCD 1998

SPCD s.d.

Telles, Vera Silva 1997

Thompson, Paulo 1992

Villela, Wilza Vieira 1999
Oficinas de humanização: fundamentação teórica e descrição de uma experiência com um grupo de profissionais de saúde. In: Deslandes, Suely Ferreira (Org.). Humanização dos cuidados em saúde: conceitos, dilemas e práticas. Rio de Janeiro: Ed. Fiocruz. p.62-71.

Considerações sobre a metodologia qualitativa como recurso para o estudo das ações de humanização em saúde. Saúde e Sociedade, São Paulo, v.13, n.3, p.44-57.

A nova divisão social do bem-estar e o retorno do voluntariado. Serviço social E sociedade, São Paulo, v.73, p.75-100.

Contingência, ironia e solidariedade. Lisboa: Presença.

Famílias, profissionais e casas de apoio: as dificuldades do cotidiano da criança soropositiva. In: Castro e Silva, Carlos Roberto (Org.). Crianças e aids: ensaios e experiências. São Paulo: Núcleo de Estudos para a Prevenção da Aids. p.49-54.

Teologia da Libertação. In: Silva, Francisco Carlos Teixeira (Org.). Enciclopédia das guerras e revoluções do século XX: as grandes transformações do mundo contemporâneo. Rio de Janeiro: Elsevier. p.885-887.

Bioética, solidariedade crítica e voluntariado orgânico. Revista de Saúde Pública, São Paulo, v.39, n.3, p.473-478.

Igreja católica, assistência social e caridade: aproximações e divergências. Sociologias, Porto Alegre, v.15, p.326-351.

Prefácio. In: Montaño, Carlos. Terceiro setor e questão social: crítica ao padrão emergente de intervenção social. São Paulo: Cortez. p.11-13.

Sociedade Padre Constanzo Dalbésio.

Plano de trabalho. São Paulo.

Sociedade Padre Constanzo Dalbésio. Biografia do padre Valeriano Paitoni. Disponível em: http://www.spcd.org.br. Acesso em: 20 maio 2004.

Direitos sociais: afinal do que se trata? Biblioteca Virtual de Direitos Humanos da Universidade de São Paulo. Disponível em: http://www.direitoshumanos.usp.br/counter/Biblio/txt/vera.html. Acesso em: 13 jun. 2005.

A voz do passado: história oral.

2.ed. Rio de Janeiro: Paz e Terra.

Das interfaces entre os níveis governamentais e a sociedade civil. In: Parker, Richard; Galvão, Jane; Bessa, Marcelo Secron (Org.). Saúde, desenvolvimento e política: respostas frente à aids no Brasil. Rio de Janeiro: Associação Brasileira Interdisciplinar de Aids. p.177-224.

Recebido para publicação em outubro de 2005.

Aprovado para publicação em março de 2007. 